Jumrotul Inayah

\title{
NASIONALISME MAHABBAH AR-RASUL: STUDI PEMIKIRAN HABIB MUHAMMAD LUTHFI BIN YAHYA 1960 M - 2016 M
}

\author{
Jumrotul Inayah \\ Institut Agama Islam Negeri Syekh Nurjati Cirebon
}

\begin{abstract}
Abstrak: Kesadaran nasionalisme harus tetap terpelihara dan terjaga pada setiap bangsa Indonesia. Semangat nasionalisme bukan hanya menjaga wilayah teritorial saja melainkan untuk pembangunan bangsa dalam berbagai aspek kehidupan, seperti dalam bidang pendidikan, ekonomi, budaya, sosial dll. Salah satu ulama thariqah yang senantiasa menggelorakan nasionalisme kepada jamaahnya adalah Habib Muhammad Luthfi bin Yahya. Sehingga penulis tertarik untuk mengkaji gagasan nasionalisme Habib Luthfi, karena diantara ulama-ulama thariqah lain yang menyebarkan gagasan nasionalisme, Habib Luthfi mempunyai pengaruh dan kontribusinya lebih besar dan merata disemua kalangan. Penulisan artikel ini menggunakan metode penelitian kualitatif deskriptif dengan kajian observasi dan kepustakaan. Hasil penelitian dan kesimpulan dapat dijelaskan bahwa; (1) menurut Habib Luthfi, nasionalisme adalah rasa cinta tanah air yang melahirkan bela Negara dan bangsa yang dimulai dengan bangga kepada bangsa dan Negara, dan bangga menjadi warga Negara Indonesia dan melahirkan rasa memiliki bangsa dan Negara; (2) gagasan nasionalisme Habib Luthfi merupakan rasa cinta kepada bangsa dan negara sebagai wujud manifestasi kecintaan beliau kepada Allah SWT dan Rasul-Nya, yang penulis sebut dengan nasionalisme Mahabbah ar-Rasul; (3) gerakan nasionalisme Habib Luthfi berlandaskan Al-Quran surat Al-Baqarah ayat 3 yang meliputi pembangunan ideologi, pembangunan sumber daya manusia, dan pembangunan ekonomi. Diharapkan hasil penelitian ini dapat menambah wawasan dan rasa nasionalisme, serta diharapkan tulisan ini dapat menjadi rujukan bagi peneliti-peneliti yang bergerak di bidang sosial.
\end{abstract}

Kata Kunci: Mahabbah Ar-Rasul, Habib Muhammad Luthfi Bin Yahya, Nasionalisme

\section{A. PENDAHULUAN}

Perjuangan rakyat Indonesia melawan penjajahan demi mendapatkan kemerdekaan harus melalui proses panjang dan lama, dan puncaknya adalah proklamasi kemerdekaan Republik Indonesia pada tanggal 17 Agustus 1945 yang diproklamasikan oleh Ir. Soekarno dan Moh. Hatta. Meskipun pasca proklamasi kemerdekaan, perjuangan belum sepenuhnya selesai karena penjajah masih berusaha menjajah kembali Indonesia, sehingga di banyak tempat meletuslah 
Jumrotul Inayah

pertempuran rakyat seperti pertempuran 10 November di Surabaya, pertempuran gerilya Panglima Soedirman, dan pertempuran Bandung Lautan Api yang dipimpin oleh Jenderal AH. Nasution.

Munculnya semangat nasionalisme dan persatuan di awal abad ke-20 ditandai dengan berdirinya organisasi-organisasi sebagai wadah perjuangan, agar perjuangan rakyat Indonesia terorganisir dengan baik, dan pada puncaknya ialah momen sumpah pemuda yang terjadi pada tanggal 28 Oktober 1928 yang menjadi titik awal munculnya semangat nasionalisme dan persatuan Indonesia ${ }^{1}$.

Keberhasilan perlawanan rakyat Indonesia melawan penjajah dan meraih kemerdekaan tidak terlepas dari peran serta Ulama dan kaum muslimin dan menjadi bukti bahwa semangat perlawanan antikolonialisme dan imperialisme berangkat dari idealisme keagamaan. Bahkan dalam banyak kasus, para Ulama memimpin umat Islam untuk memerangi penjajah dan raja yang berkolaborasi dengan penjajah ${ }^{2}$. Sebagai contoh perlawanan rakyat Banten yang dipimpin oleh Mursyid Thariqah Al-Qadiriyyah wa An Naqsybandiyyah, KH. Abdul Karim, perlawanan santri Cirebon atau perang kedondong yang dipimpin Mursyid Thariqah Syatthariyyah KH. Muqayyim dan KH. Hasanuddin (Ki Jatira), Perang Jawa yang dipimpin oleh Syekh Abdul Hamid atau Pangeran Diponegoro yang juga Mursyid Thariqah Al Qadiriyyah ${ }^{3}$. Inilah alasan mengapa dalam pikiran umat Islam perang melawan penjajah adalah jihad. Akan tetapi, semangat perlawanan itu bersifat sporadis dan tanpa ikatan penyatu sehingga berakhir dengan kekalahan.

\footnotetext{
${ }^{1}$ Oon Syukron Maemun, "Kontekstualisasi Makna Sumpah Pemuda di Era Globalisasi", Damardjati MATAN Cirebon, Edisi Oktober 2014, h. 1-2.

${ }^{2}$ Djohan Efendi, Pembaruan Tanpa Membongkar Tradisi: Wacana Keagamaan di Kalangan Generasi Muda NU Masa Kepemimpinan Gus Dur (Jakarta: Kompas, 2010), h. 50.

${ }^{3}$ Ceramah Habib Luthfi bin Ali bin Yahya dalam Haul Sulthan Abdul Fattah Demak Tahun 2012. Sumber rekaman koleksi pribadi Syukron Ma"emun (Mantan Sekretaris Pribadi Habib Luthfi).
} 
Dewasa ini kecintaan terhadap tanah air Indonesia dipandang mulai meluntur. Kondisi tersebut dibuktikan diantaranya dengan beberapa contoh kasus, seperti tidak bangga menjadi bangsa Indonesia, lebih memilih membeli produk luar Negeri daripada produk dalam Negeri, merebaknya kebencian dan ketidakpercayaan terhadap Pemerintah, dan maraknya organisasi dan gerakan transnasional yang menebarkan kebencian terhadap Negara dengan mengatasnamakan Islam, seperti Hizbut Tahrir. Berdasarkan analisis yang penulis lakukan, setidaknya ada beberapa alasan melenturnya kecintaan terhadap tanah air, diantaranya disebabkan pemberitaan media massa yang lebih menonjolkan keburukan atau sisi negatif Indonesia seperti pemberitaan besarbesaran atas korupsi pejabat dan ketimpangan ekonomi yang menyebabkan melunturnya bahkan hilangnya rasa bangga terhadap bangsa dan Negara. Di samping itu, upaya sekularisasi Negara yang diciptakan oleh penjajah dengan menyebarkan pemahaman di masyarakat bahwa kecintaan terhadap tanah air bukanlah ibadah yang menyebabkan sebagian elit agama atau ulama ikut terbawa arus tersebut dengan hanya menyampaikan perihal ibadah mahdhah saja seperti shalat, zakat, dan puasa dalam pengajian dan tidak menyampaikan pentingnya nasionalisme di tengah umat sehingga umat pun berfikir bahwa mencintai tanah air bukan ibadah dan bukan bagian ajaran agama Islam.

Selain itu, sejak orde reformasi bergulir yang juga mulai munculnya kebebasan berekspresi membuat beberapa kelompok anti nasionalisme dan anti pancasila bermunculan, termasuk berani mendeklarasikan diri di hadapan umum, seperti Hizbut Tahrir Indonesia (HTI), Jama ${ }^{e e} a h$ Ansharut Tauhid (JAT), dan Majelis Mujahidin Indonesia (MMI). Dalam situs resminya, HTI menyebutkan bahwa semua sistem dan hukum selain sistem dan hukum Islam seperti sekulerisme, liberalisme, dan demokrasi adalah sistem kufur yang harus 
ditinggalkan oleh umat Islam. Umat Islam seluruh dunia harus bersatu menegakkan sistem khilafah rasyidah yang bisa menerapkan hukum Islam secara $\mathrm{kaffah}^{4}$.

Adapun MMI tidak mewajibkan berdirinya khilafah sebagaimana HTI. Sebagaimana dimuat dalam situs resminya, MMI hanya mewajibkan diterapkannya syariah Islam di Indonesia dengan tetap menghormati pemeluk agama lain ${ }^{5}$. Meskipun dalam perkembangannya beberapa tokoh MMI seperti Abu Bakar Ba"easyir (pada tahun 2008 keluar dan mendirikan JAT) dan Abu Muhammad Jibril. Bahkan Abu Muhammad Jibril dalam acara Bekasi Bersyariah mengeluarkan statemen yang menyatakan bahwa siapa saja yang mengikuti Pancasila akan binasa dan tidak selamat ${ }^{6}$. Selain organisasi-organisasi dan tokohtokoh transnasional seperti yang disebutkan di atas, beberapa Kiai dari Nahdlatul Ulama pun menyuarakan ketidaksepakatannya terhadap Pancasila dan mendukung upaya yang dilakukan oleh HTI dan MMI. Sebagaimana yang pernah disampaikan oleh KH. Ahmad Hasan dari Megu Plered kepada Syukron Maeemun dan aktivis MATAN Cirebon ${ }^{7}$. KH. Ahmad Hasan mengatakan bahwa perjuangan yang dilakukan oleh HTI itu wajib didukung. Orang Islam kalau mendukung Pancasila dan sampai tidak mendukung diterapkannya hukum syariat Islam itu bisa dihukumi fasik bahkan kafir ${ }^{8}$.

${ }^{4}$ DPP. Hizbut Tahrir Indonesia, "Bersama Umat Tegakkan Khilafah", http://hizbuttahrir.or.id/2015/06/03/bersama-umat-tegakkan-khilafah-3/, diakses tanggal 16 Desember 2015 pukul 06.20 WIB.

${ }^{5}$ Majelis Mujahidin Pusat, "Mengenal Majelis Mujahidin", http://www.majelismujahidin.com/about/mengenal-majelis-mujahidin/, diakses pada tanggal 16 Desember 2015 pukul 06.25 WIB.

${ }^{6}$ Sayed Azhar, "Abu Jibril: Yang Ikut Pancasila Akan Binasa dan Tidak Selamat", http://www.statusaceh.com/2015/11/abu-jibril-yang-ikut-pancasila-akan.html, diakses pada tanggal 16 Desember 2015 pada pukul 06.30 WIB.

${ }^{7}$ MATAN adalah Mahasiswa Ahlith Thariqah Al Muetabarah An Nahdliyyah yang didirikan dan dideklarasikan oleh Habib Luthfi bin Yahya pada Januari 2012 di Malang.

${ }^{8}$ Informasi dari Syukron Maemun yang bersama dengan aktivis MATAN Cirebon bersilaturrahim ke kediaman KH. Ahmad Hasan di Megu Plered pada tanggal 29 Agustus 2015. 
Selain itu, ada juga KH. M. Afif Hasan dari Sumenep yang dalam bukunya yang berjudul Kapita Selekta Yurisprudensi Islam mempertanyakan pernyataan dan sikap tokoh-tokoh NU yang mendukung Pancasila. Lebih lanjut, Afif Hasan mendukung penerapan syariah Islam di Indonesia dengan mengganti semua peraturan perundang-undangan yang dinilai tidak sesuai dengan syariah Islam ${ }^{9}$. Akan tetapi, di tengah kurangnya ulama yang bersuara tentang pentingnya nasionalisme, dan semakin derasnya suara anti nasionalisme, masih terdapat beberapa ulama yang dalam pengajiannya selalu bersuara tentang pentingnya nasionalisme, diantaranya adalah Habib Muhammad Luthfi bin Ali bin Yahya Pekalongan (Rais „Am Idarah Aliyah Jam"iyyah Ahlith Thariqah Al Mu"tabarah An Nahdliyyah). Bahkan tradisi menyanyikan lagu Indonesia Raya di setiap penutupan pembacaan maulid Nabi yang dipimpin oleh Habib Syekh bin Abdul Qadir As Segaf pun atas perintah dari Habib Muhammad Luthfi bin Yahya ${ }^{10}$.

Melihat kondisi demikian, penulis tertarik untuk melakukan penelitian tentang ajaran nasionalisme menurut pandangan Habib Muhammad Luthfi bin Yahya Pekalongan. Alasan penulis memilih kajian penelitian tentang ajaran nasionalisme menurut pandangan Habib Muhammad Luthfi bin Yahya karena dewasa ini jarang ditemukan ulama thariqah yang begitu bersemangat menggelorakan ajaran nasionalisme di tengah umat meskipun diakui pula bahwa penggerak perlawanan terhadap penjajah banyak dari kalangan mursyid thariqah. Umumnya ulama thariqah hanya berbicara tentang thariqah, tasawwuf, dan ibadah mahdhah. Berpijak pada latar belakang yang telah penulis paparkan, maka penelitian yang berjudul "Nasionalisme Mahabbah Ar-Rasul (Studi Pemikiran Habib Muhammad Luthfi bin Yahya Pekalongan 1960 M - 2016 M)” perlu

\footnotetext{
${ }^{9}$ M. Afif Hasan, Kapita Selekta Yurisprudensi Islam; kajian kitab kuning tentang pernakpernik ibadah dan tradisi (Malang: Maktabah Publishing, 2009), h. 153-166.

${ }^{10}$ Syukron Ma"mun (mantan sekretaris pribadi Habib Muhammad Luthfi bin Yahya), wawancara (Cirebon: 5 Mei 2016).
} 
dilakukan. Karena melalui penelitian ini akan diperoleh gambaran yang obyektif, komprehensif, dan sistematis mengenai gagasan nasionalisme Habib Muhammad Luthfi bin Yahya Pekalongan.

\section{B. METODE PENELITIAN}

Dalam penelitian ini penulis menggunakan metode kualitatif. Metode kualitatif merupakan suatu prosedur yang menghasilkan data deskriptif berupa kata-kata tertulis atau lisan dari orang-orang dan prilaku yang dapat diamati. Untuk melakukan penelitian mengenai gagasan nasionalisme seorang tokoh bernama Habib Muhammad Luthfi bin Yahya, peneliti menggunakan pendekatan fenomenologi. Hal itu dikarenakan fenomenologi dapat diimplementasikan untuk kajian tarekat. Habib Muhammad Luthfi bin Yahya, sebagai seorang tokoh, tentu tak bias terlepas dari tarekat, karena Habib Luthfi merupakan mursyid tarekat dan Rais'Aam Jamiyyah Ahlith Thariqah Al Muetabarah An Nahdliyyah (JATMAN/organisasi yang mewadahi tarekat-tarekat mu'tabarah).

Dalam rangka upaya memahami sesuatu di balik fenomena dan menemukan kesadaran murni, fenomenologi mengajarkan tiga tahapan reduksi, yaitu: (1) reduksi fenomenologis, yaitu kesadaran tentang adanya fenomena di sekeliling kita yang dirasakan kehadirannya dan dialami dalam ruang dan waktu; (2) reduksi eidetic, yaitu penghayatan ideal, dimana seseorang dapat memahami pemikiran, kesadaran dan tindakan orang berdasarkan atas ide-ide atau pikiran dan kesadaran yang dimilikinya; dan (3) reduksi transendental, yaitu proses untuk menemukan subjek murni dengan bergerak dari balik keseharian kepada ego murni. Hasilnya adalah pemahaman intersubjektif atau proses keluar menjadi paham. 


\section{HASIL DAN PEMBAHASAN}

\section{Gagasan Nasionalisme Muhammad Luthfi bin Yahya}

Habib Muhammad Luthfi bin Yahya merupakan ulama thariqah yang terkenal getol menyuarakan nasionalisme di banyak tempat, baik itu dalam pengajian umum maupun dalam seminar ilmiah. Bahkan, penyebaran gagasan nasionalisme beliau juga melibatkan organisasi yang beliau pimpin, yaitu Jamiyyah Ahlith Thariqah Al Mu'tabarah An Nahdliyyah (JATMAN/ Organisasi yang mewadahi thariqah-thariqah mu'tabarah). Nasionalisme Habib Luthfi -demikian beliau dikenal secara umum- bukan tanpa landasan historis dan tanpa pengalaman pribadi yang beliau alami. Habib Luthfi menyatakan bahwa mayoritas guru beliau mengajarkan untuk mencintai bangsa dan Negara ini. Akan tetapi, lanjut beliau, ada dua orang yang sangat menginspirasi kecintaan beliau terhadap tanah air, yaitu Habib Ali bin Hasyim bin Yahya (Ayah beliau), dan Syaikh Muhammad Abdul Malik (Guru beliau/Purwokerto).

Habib Luthfi bercerita bahwa suatu hari beliau melepas bendera merah putih seusai peringatan hari kemerdekaan. Sebagai anak kecil, Habib Luthfi melepas bendera merah putih dari bambu, dan meletakkannya di tanah. Melihat hal itu, Ayah beliau marah dan memukul Habib Luthfi kecil sambil berkata," $I k i$ bendero ora mung bendera werno abang putih, tapi ono nyowo, harta sing dikorbanke supoyo bendero iki iso dipasang. Ojo sembarangan. Kudu ngormati pejuang sing wes berkorban" (Bendera ini bukan hanya bendera berwarna merah putih. Tapi ada nyawa, dan harta yang dikorbankan agar bendera ini bias dipasang. Jangan sembarangan. Harus menghormati pejuang yang sudah berkorban untuk tegaknya bendera ini). Sejak kejadian itu, Habib Luthfi berhati 
hati membawa dan menyimpan bendera merah putih, dan mulai tumbuh kesadaran untuk mencintai tanah air ${ }^{11}$.

Habib Luthfi juga bercerita perihal Mbah Malik (panggilan terhadap Syaikh Muhammad Abdul Malik) dalam mengungkapkan kecintaan terhadap tanah air. Mbah Malik yang pernah ikut berjuang melawan penjajah dan putra dari pejuang, serta keturunan dari Pangeran Diponegoro ini tiap kali tanggal 17 Agustus pada pukul 10.00 selalu diam, mengirim doa dan surat al Fatihah untuk para pejuang dan pahlawan. Nasionalisme Habib Luthfi juga tidak terlepas dari sosok beliau yang cinta sejarah. Habib Luthfi sendiri mulai mempelajari sejarah sejak tahun 1960. Beliau menuturkan,'Sejak tahun 1960, saya mulai jarang tidur malam untuk membaca dan mempelajari buku-buku dan manuskrip-manuskrip sejarah dan mempelajari nisan-nisam makam auliya". Sehingga beliau paham akan sejarah bangsa Indonesia, mulai zaman kerajaan sampai sejarah Indonesia era modern. Habib Luthfi menjelaskan bahwa tanpa mengetahui sejarah bangsa, maka kita menjadi generasi yang tidak punya jati diri bangsa dan tidak bangga kepada bangsa dan Negara. Kalau sudah tidak bangga pada bangsa dan Negara, maka tidak mungkin muncul rasa cinta terhadap tanah air.

Habib Luthfi menegaskan bahwa sejarah itu harus dipelajari dan dipahami. Dari sejarah kita mengetahui kebesaran kerajaan-kerajaan di Nusantara, kemajuan peradaban di Nusantara, dan begitu berwibawanya kerajaan-kerajaan di bumi Nusantara, sebagai contoh pada masa Dinasti Syailendra dengan borobudurnya, masa Sriwijaya dengan kemajuan perdagangannya, masa Majapahit dengan kekuatan militer yang ditakuti dan disegani. Bahkan ulama-ulama dari Nusantara pun banyak yang terkenal dan menjadi ulama besar di dunia Islam. Itu semua menandakan bahwa bangsa

\footnotetext{
${ }^{11}$ Keterangan mengenai ini penulis peroleh dari Habib Luthfi bin Yahya dalam obrolan bersama beliau dengan tamu-tamu beliau pada hari jumat tanggal 20 Mei 2016.
} 
Indonesia bukan bangsa yang bodoh dan terbelakang. Sehingga generasi penerus bangsa harus bangga dan termotivasi untuk kemajuan dan kejayaan bangsa ${ }^{12}$.

Dalam memaknai nasionalisme, Habib Luthfi mengatakan bahwa nasionalisme adalah rasa cinta tanah air yang melahirkan bela Negara dan bangsa. Lebih lanjut, Habib Luthfi menjelaskan bahwa munculnya rasa cinta tanah air dimulai dengan bangga kepada bangsa dan Negara, dan bangga menjadi warga Negara Indonesia. Kemudian kebanggaan itu memunculkan rasa memiliki, menghargai, dan menghormati bangsa dan Negara dengan segala kekurangan dan kelebihannya, termasuk didalamnya adalah menghargai dan menghormati pemerintah, TNI, dan Kepolisian. Habib Luthfi menambahkan, adanya rasa bangga dan rasa memiliki terhadap bangsa ini merupakan awal mula dan bekal utama munculnya rasa cinta terhadap tanah air. Ketika cinta terhadap tanah air sudah tumbuh, dan kuat, maka yang terlihat itu keindahan dan kabaikan. Kalau ada kekurangan, maka orang yang cinta tanah air tidak akan menampakkan kekurangan tanah airnya di hadapan umum, tetapi menganggap bahwa kekurangan itu adalah tugas baginya untuk ikut serta membangun Negara. Sehingga muncul upaya bela Negara. Habib Luthfi mengatakan bahwa bela Negara bukan hanya tugas TNI, dan Kepolisian. Tetapi tugas semua warga Negara. Menurut Habib Luthfi, bela Negara merupakan upaya nyata membangun Negara dan tidak terbatas hanya bidang pertahanan dan keamanan Negara seperti wajib militer. Sehingga dalam praktek sekarang ini bela Negara itu dilakukan di semua bidang, seperti pendidikan, ekonomi, sosial, politik, pertanian, peternakan, dan budaya. Habib Luthfi juga menegaskan bahwa nasionalisme ini

\footnotetext{
12 Pentingnya mempelajari sejarah sering disampaikan oleh Habib Luthfi pada banyak kesempatan, baik itu saat berbincang dengan tamu atau saat memberi ceramah maulid Nabi, seperti saat penulis berkunjung dan bertamu di kediaman beliau di Kota Pekalongan pada hari Selasa, 19 April 2016 pukul 09.00 WIB.
} 
bukan perilaku ashabiyyah (fanatisme sempit atau chauvinisme), tetapi sebagai wujud syukur kepada Allah SWT karena telah menjadi bangsa Indonesia ${ }^{13}$.

\section{Dalil Naqli Nasionalisme Mahabbah Ar-Rasul}

KH. Abdullah Saeead65 dalam suatu kesempatan diskusi di kediaman Habib Luthfi menyampaikan sebuah dalil nasionalisme atau cinta tanah air dari surat Al-Baqarah ayat 126, "Dan (ingatlah), ketika Ibrahim berdoa, "Ya Tuhanku, jadikanlah negeri ini (Makkah) aman, dan berilah rezeki berupa buah-buahan kepada penduduknya. KH. Abdullah Sa ${ }^{e e}$ ad dalam menjelaskan ayat tersebut mengatakan,"Dalam ayat itu Nabi Ibrahim berdoa memohon Negerinya aman. Waktu itu beliau tinggal di Makkah. Kalau kita tarik ke dalam konteks Indonesia, tentu kita pun harus berdoa agar Indonesia aman. Doa Nabi Ibrahim itu juga menjadi pelajaran dan contoh bagi kita agar kita berusaha menjadikan daerah kita, Negara kita aman. Nabi Ibrahim berdoa menggunakan الآهك ، bukan اجعم artinya harus ada ikhtiar untuk mewujudkan agar aman, bukan sekedar berdoa”.

Habib Luthfi yang ikut serta hadir dalam diskusi mendengarkan dan diam. Beliau tidak memotong penjelasan atau menyanggah penjelasan $\mathrm{KH}$. Abdullah Saeead. Akan tetapi, beliau menambahkan keterangan dari $\mathrm{KH}$. Abdullah Sa"ead sebagai berikut, "Perlu dipahami, Makkah penuh berkah dan istimewa itu juga berkah doa dari Nabi Ibrahim. Kemudian ayat itu perlu dipahami pula secara kontekstual. Semisal dalam ayat tersebut Nabi Ibrahim meminta diberi rezeki oleh Allah berupa buah-buahan. Itu isyarat bagi kita agar kita berusaha menghidupkan sector pertanian. Ingat, ats-tsamarat, buah-buahan itu masuk pula dalam sektor pertanian yang meliputi pertanian padi, sayuran,

\footnotetext{
${ }^{13}$ Disarikan dari pidato Habib Muhammad Luthfi bin Yahya pada penutupan KonferensiInternasional Ulama Thariqah Bela Negara pada 15 Januari 2016 di Hotel Santika Kota Pekalongan. Penulis merupakan peserta konferensi.
} 
buah-buahan, dan lain-lain"14. Nasionalismenya Habib Luthfi ialah cinta tanah air yang berlandaskan kecintaan terhadap Nabi Muhammad SAW. Demikian sebagaimana ditulis oleh $\mathrm{KH}$. Abdullah $\mathrm{Sa}^{e e} \mathrm{ad}$. Hal tersebut, menurut $\mathrm{KH}$. Abdullah Saeead, adalah bukti bahwa Habib Luthfi bin Yahya mempunyai cinta yang kuat terhadap Rasulullah SAW. sehingga, sebagai orang yang cinta akan berusaha sekuat tenaga mengikuti teladan Rasulullah SAW dalam memakmurkan bumi, yaitu mewujudkan tatanan kehidupan manusia yang penuh kedamaian. 68

Maka ketika Habib Luthfi menyampaikan ceramah dengan materi tentang cinta Rasulullah, bisa dipastikan Habib Luthfi akan menarik makna kecintaan terhadap Rasulullah itu kepada kecintaan terhadap Ahlul Bait, para sahabat, para ulama dan auliya, dan kecintaan terhadap tanah air. Selain itu, bukti bahwa nasionalismenya Habib Luthfi meniru perilaku Rasulullah SAW. adalah dasar hadits Rasulullah SAW. "Cintailah Arab karena tiga hal: karena saya bangsa Arab, Al Quran berbahasa Arab, dan bahasa penduduk surga adalah bahasa $A r a b " 15$. Ketika menjelaskan hadits tersebut, Habib Luthfi mengatakan,"Itu merupakan contoh dari Baginda Nabi SAW, contoh apa? Contoh bahwa beliau mencintai Arab sebagai bangsanya. Maka kalau kita sebagai umat Baginda Nabi yang lahir di Indonesia, tentunya harus mencontoh dan mengikuti Baginda Nabi dengan cara mencintai Indonesia ini”.

\footnotetext{
${ }^{14}$ Penulis memperoleh rekaman suara diskusi dari Syukron Maemun. Diskusi dilakukan pada Ramadhan 1436 H di Gedung Kanzus Shalawat Kota Pekalongan (tidak ada ketengan waktu pelaksanaan). Ahmad Tsauri dalam Sejarah Maulid Nabi juga sedikit menyinggung tentang diskusi ini. Lihat Ahmad Tsauri,"Sejarah Maulid Nabi (Meneguhkan Semangat Keislaman dan Kebangsaan): Sejak Khaizuran (173 H) Hingga Habib Luthfi bin Yahya (1947 MSekarang)", 2015, h. 242.

${ }^{15}$ Habib Ali Zainal Abidin Assegaf, wawancara (Kanzus Shalawat Pekalongan, 22 Mei 2016 pukul 13.00 WIB). Adapun Redaksi lengkap hadits penulis kutip dari http://www.pissktb.com/2015/03/3994-hadits-cintailah-orang-arab.html?m=0, diakses pada tanggal 23 Mei 2016 pukul 08.00 WIB.
} 
Cinta tanah air, menurut Habib Luthfi, merupakan wujud terima kasih atau syukur kepada tanah air tempat lahir dan hidup. Karena, menurut beliau, tidak mungkin seseorang bisa bersyukur kepada Allah tanpa syukur kepada makhluk, maka terima kasih atau syukur kepada tanah air ini merupakan perwujudan syukur kepada Allah. Adapun syukur dalam Islam itu hukumnya wajib $^{16}$. Habib Luthfi menambahkan, kemerdekaan Indonesia ini bukan diperoleh secara gratis. Ada nyawa, harta, dan keluarga yang dikorbankan. Seandainya Negara ini belum merdeka, maka semua warga Negara Indonesia sekarang ini tidak bisa beribadah dengan tenang, bekerja dengan tenang, dan belajar dengan tenang. Begitu pula jika kondisi Negara secara politik dan keamanan tidak stabil. Maka harus ada ucapan terima kasih dan syukur terhadap para pejuang dan pendiri bangsa ini, dan syukur bukan hanya dengan ucapan atau lisan, tetapi juga dengan perbuatan. Masih menurut Habib Luthfi, nasionalisme atau cinta tanah air jika dahulu terbukti efektif untuk menyatukan beragam suku, bangsa, etnis, dan agama menuju cita-cita Indonesia merdeka, maka kini penting terus digelorakan untuk menghindari dan mencegah ancaman disintegrasi bangsa. Sebab kalau terus menerus terjadi gejolak, perpecahan, tawuran antar penduduk maka kapan pemerintah akan fokus membangun. Oleh sebab itu, dalam pandangan Habib Luthfi gerakan penyadaran cinta tanah air juga merupakan bagian dari pembangunan bangsa ${ }^{17}$.

Fenomena nasionalisme Habib Luthfi, dalam sudut pandang kajian fenomenologi, menurut penulis bukan nasionalisme murni yang hanya berlandaskan kecintaan terhadap bangsa dan Negara. Akan tetapi, penulis

\footnotetext{
${ }^{16}$ Syaikh'Abdul Qadir'Isa, Hakekat Tasawuf, terj. Khairul Amru Harahap dan Afrizal Lubis (Jakarta: Qisthi Press, 2011), h. 268.

${ }^{17}$ Disarikan dari ceramah Habib Luthfi pada Maulid Nabi "Kanzus Sholawat" di kediaman Habib Ali Zainal Abidin As Segaf Jl. Toba Kota Pekalongan pada hari kamis malam jumat, 19 Mei 2016.
} 
menilai bahwa nasionalisme atau cinta tanah air yang selama ini didengungkan merupakan manifestasi kecintaan beliau kepada Allah SWT. dan Rasulullah Muhammad SAW. seperti yang disampaikan beliau pada panitia Maulid Nabi asal Kebumen yang bertanya tarif dakwah kepada beliau. Dengan nada tinggi dan nada sedikit marah beliau mengatakan: "Saya ini ceramah kesana kemari, Maulid kesana kemari bukan karena uang atau materi dunia. Andaikan saya diberi uang satu kamar penuh saya tidak memandangnya. Bahkan andaikan gunung Slamet menjadi emas 24 karat itu tidak mampu membayar satu ayat yang saya bacakan saat ceramah, apalagi ditambah dengan hadits, shalawat dan doa. Semua saya lakukan karena itu adalah perintah dari Rasulullah SAW."

Terkait dengan hal itu, ketika Habib Ahmad bin Muhammad bin Smith pada Awal april datang ke Habib Luthfi dan meminta Habib Luthfi untuk ceramah di tempat beliau dengan waktu yang sudah ditetapkan oleh Habib Ahmad, Habib Luthfi berkata pada Habib Ahmad,'Bib, nek tanggal sakmono aku ora wan ninggalke. Soale iku tanggal sing dadi tuan rumah daerah minus pengetahuan agamane. Nang daerah iku aku ora malah dibayar, tapi malah aku ngeke"I beras,

wedus lan duit nang panitiane (Bib, kalau tanggal segitu saya tidak berani. Karena di tanggal itu yang jadi tuan rumah daerah yang jadi tuan rumahnya daerah yang minus pengetahuan agamanya. Malahan di daerah itu saya tidak dibayar, tetapi malah memberi beras, kambing, dan uang ke panitia)'. Penulis berpendapat demikian karena dari beberapa ceramah maulid Nabi dan pengajian thariqah oleh Habib Luthfi yang penulis dengar melalui langsung atau rekaman, Habib Luthfi selalu mengawali pembahasan nasionalisme atau cinta tanah air dengan pembahasan mengenai cinta terhadap Allah SWT. Dan Rasulullah SAW. seperti perkataan beliau dalam Maulid PP. al- Mumajjad Limbangan, beliau berkata: "Rasulullah SAW bersabda kadar bobot keimanan seseorang 
tergantungkadar bobot kecintaannya padaku. Nah ini oleh oknum-oknum yang tidak

bertanggung jawab makna hadits ini dibalik untuk melemahkan Islam dan dalam konteks negara melemahkan NKRI. Maksudnya apa? Jauhkan umat dari rasa cinta kepada baginda Nabi. Dengan cara apa? Jauhkan umat dari ahlul bait dan para ulama. Adapun dalam konteks Indonesia, jauhkan dari rasa bangga terhadap Indonesia dan rasa hormat terhadap ulil amri. Maka tidak heran jika sekarang ini keburukan pemerintah diumbar, kejelekan Negara diumbar. Tujuannya apa? Tujuannya agar kita tidak cinta dan tidak bangga terhadap Indonesia. Jadi buah maulid Nabi ialah, tumbuhnya rasa cinta kepada Rasulullah, ahlul bait, para shahabat, para auliya dan ulama dan kecinntaan terhadap tanah air."

Selain itu, sarana utama yang digunakan oleh Habib Luthfi dalam penyebaran gagasan nasionalisme yang berupa peringatan Maulid Nabi dan thariqah semakin menguatkan kesimpulan penulis. Karena dalam peringatan Maulid Nabi yang dibacakan adalah riwayat hidup Nabi Muhammad SAW dengan harapan agar orang yang hadir mengenal Nabi dan bisa meniru akhlak Nabi. Adapun dalam thariqah, murid thariqah diajarkan untuk selalu ingat Allah SWT. dan berusaha mengenal Allah SWT., dan diantara kewajiban murid thariqah ialah patuh secara total kepada mursyidnya. Dan kecintaan terhadap tanah air yang dimiliki oleh Habib Luthfi dan disebarkan oleh Habib Luthfi, menurut penulis, adalah salah satu contoh murid yang patuh secara total kepada mursyidnya.

Hal lain yang mendukung pendapat penulis ialah aplikasi nasionalisme Habib Luthfi yang menurut pandangan penulis sebagai bentuk menjalankan perbuatan yang pernah dilakukan oleh Rasulullah atau perbuatan yang diperintahkan oleh Rasulullah SAW. seperti dalam bidang kemandirian ekonomi dan menjaga persatuan. Habib Luthfi secara tegas ingin meniru apa yang 
dilakukan oleh Rasulullah SAW. pada awal hijrah ke Madinah. "Ketika di Mekkah Rasulullah fokus membangun ideologi. Adapun ketika di Madinah dua hal yang fokus digarap oleh Rasulullah SAW adalah ekonomi dan sumber daya manusia. Karena Rasulullah sadar, tanpa ditopang ekonomi umat yang kuat, maka dakwah Rasulullah tidak bias berjalan secara maksimal. Wujudnya apa? Rasulullah menunjuk beberapa sahabat seperti sahabat Utsman bin Affan dan Abdurrahman bin Auf untuk "menguasai" pasar madinah. Hasilnya adalah pasar madinah berubah menjadi pasar yang penuh dengan adab Islam dan berhasil membangun jaringan ekonomi yang luas dan kuat. Bahkan perang badar disebabkan kaum kafir yang berusaha memutus jaringan ekonomi umat Islam dengan luar Madinah.” Berdasarkan konsepsi fenomenologi maka dipastikan ada in order to motives yang menjadi basis atas tindakan Habib Luthfi.

Habib Luthfi melakukan suatu tindakan pasti didasari oleh sesuatu yang menjadi tujuan beliau, dan tujuan itu tentunya internal diri sendiri. Oleh karena itu, penulis menyimpulkan bahwa gagasan nasionalisme Habib Luthfi bukan murni nasionalisme yang berlandaskan cinta bangsa dan Negara belaka, tetapi nasionalisme sebagai wujud atau manifestasi kecintaan kepada Allah SWT. dan Rasulullah SAW. dengan harapan memperoleh kecintaan dari Allah SWT. dan Rasulullah SAW atau menurut penulis konsep nasionalisme Habib Luthfi bernama Nasionalisme Mahabbah Ar-Rasul. Di samping itu, kecintaan terhadap Allah SWT. dan Rasul-Nya melahirkan sikap kasih sayang kepada makhluk, termasuk diantaranya adalah kecintaan terhadap tanah air. Kecintaan kepada Allah SWT. dan Rasul-Nya pula yang menurut penulis bukan hanya sebagai landasan nasionalisme dan pemberi energi tanpa batas Habib Luthfi, akan tetapi juga menjadikan ikhtiar penyebaran gagasan nasionalisme yang dilakukan oleh Habib Luthfi mudah diterima dan masuk ke dalam hati masyarakat. 


\section{KESIMPULAN}

Dalam memaknai nasionalisme, Habib Luthfi mengatakan bahwa nasionalisme adalah rasa cinta tanah air yang melahirkan bela Negara dan bangsa. Lebih lanjut, Habib Luthfi menjelaskan bahwa munculnya rasa cinta tanah air dimulai dengan bangga kepada bangsa dan Negara, dan bangga menjadi warga Negara Indonesia. Kemudian kebanggaan itu memunculkan rasa memiliki, menghargai, dan menghormati bangsa dan Negara dengan segala kekurangan dan kelebihannya, termasuk didalamnya adalah menghargai dan menghormati pemerintah, TNI, dan Kepolisian. Nasionalisme Habib Luthfi merupakan nasionalisme mahabbah Ar-Rasul, yaitu rasa cinta kepada bangsa dan negara sebagai wujud manifestasi kecintaan beliau kepada Allah SWT dan Rasul-Nya, dengan mengharapkan ridha Allah dan Rasul-Nya. Nasionalisme mahabbah ArRasul sebagai sebuah ideologi disuarakan dan digerakkan oleh Habib Luthfi melalui media Maulid Nabi dan thariqah. Sehingga dalam setiap peringatan Maulid Nabi dan kegiatan thariqah, kental dengan nuansa dan pesan nasionalisme. Aplikasi nasionalisme mahabbah Ar-Rasul dilakukan dengan ikut serta dalam pembangunan bangsa dan Negara dengan berlandaskan pada surat Al-Baqarah ayat 3 yang poinnya adalah (1) pembangunan ideologi, (2) pembangunan sumber daya manusia, dan (3) pembangunan ekonomi.

Diantara wujud aplikasi nyata nasionalisme yang dilakukan oleh Habib Luthfi ialah tradisi menyanyikan lagu Indonesia Raya pada peringatan mauled Nabi, kirab merah putih di Kalimantan Timur yang berbatasan dengan Malaysia, merekatkan hubungan ulama thariqah dengan TNI dan Polri, kampanye cinta produk dalam Negeri, termasuk keengganan beliau memakan buah impor, dan menggerakkan dan memberi contoh kepada murid-murid beliau untuk berwirausaha dan membangkitkan ekonomi umat dan bangsa. 


\section{DAFTAR PUSTAKA}

Azhar, Sayed. 2015. “Abu Jibril: Yang Ikut Pancasila Akan Binasa dan Tidak Selamat" (online) (http://www.statusaceh.com/2015/11/abu-jibril-yangikutpancasila-akan.html. diakses pada tanggal 16 Desember 2015 pada pukul 06.30 WIB).

DPP Hizbut Tahrir Indonesia. 2015. "Bersama Umat Tegakkan Khilafah" (online) (http://hizbut-tahrir.or.id/2015/06/03/bersama-umat-tegakkankhilafah-3/, diunduh tanggal 16 Desember 2015 pukul 06.20 WIB).

Efendi, Djohan. 2010. Pembaruan Tanpa Membongkar Tradisi. Jakarta: Kompas.

Hasan, M. Afif. 2009. Kapita Selekta Yurisprudensi Islam; kajian kitab kuning tentang pernak-pernik ibadah dan tradisi. Malang: Maktabah Publishing.

Idarah 'Aliyah Jamiyyah Ahlith Thariqah Al Mu’tabarah An Nahdliyyah. 2006. Permasalahan Thariqah: Hasil Kesepakatan Muktamar dan Musyawarah Besar Jam "iyyah Ahlith Thariqah Al Mu"tabarah Nahdlatul „, Ulama (1957-2005). Surabaya: Khalista dan PP. Al-Aziziyyah Denanyar.

Isa, Syaikh Abdul Qadir. 2011. Hakekat Tasawuf. Terjemahan oleh Khairul Amru Harahap dan Afrijal Lubis dari Haqa"iq at-Tashawwuf. Jakarta: Qisthi Press.

Majelis Mujahidin Markaz Pusat. "Mengenal Majelis Mujahidin” (online) (http://www.majelismujahidin.com/about/mengenal-majelis-mujahidin/, diunduh pada tanggal 16 Desember 2015 pukul 06.25 WIB).

Maemun, Oon Syukron. 2014. Kontekstualisasi Makna Sumpah Pemuda di Era Globalisasi. Artikel Buletin Damardjati Edisi Oktober 2014. Cirebon: MATAN. 
Ma"emun, Syukron. 2016. "Konsensus Bela Negara Hasil Konferensi Ulama Thariqah"(online),(http://www.habiblutfi.net/index.php/berita/item/491konsensus-bela-negara-hasil-konferensi-ulama-thariqah-2016, diunduh pada tanggal 22 Mei 2016 pukul $10.00 \mathrm{WIB})$.

Muhammad Luthfi bin Yahya, Al Habib. 2012. "Secercah Tinta; jalinan cinta seorang hamba dengan Sang Pencipta”, Editor Ahmad Tsauri, Pekalongan: Menara Publisher. 